EGU2020-8274, updated on 19 May 2020

https://doi.org/10.5194/egusphere-egu2020-8274

EGU General Assembly 2020

(c) Author(s) 2020. This work is distributed under

the Creative Commons Attribution 4.0 License.

\title{
Constraining subglacial geology using ambient noise Rayleigh wave ellipticity
}

\author{
Glenn Jones ${ }^{1,2}$, Bernd Kulessa ${ }^{1,3}$, Ana Ferreira ${ }^{2}$, Martin Schimmel ${ }^{4}$, Andrea Berbellini ${ }^{5}$, and Andrea \\ Morelli ${ }^{5}$ \\ ${ }^{1}$ Swansea University, Swansea, UK \\ ${ }^{2}$ University College London, London, UK \\ ${ }^{3}$ University of Tasmania, Hobart, Australia \\ ${ }^{4}$ Instituto de Ciencias de la Tierra Jaume Almera, Barcelona, Spain \\ ${ }^{5}$ Istituto Nazionale di Geofisica e Vulcanologia, Bologna, Italy
}

Basal slip is an important mechanism by which glaciers and ice-sheets flow, and is a major source of uncertainty in simulations of ice-mass loss and sea level rise from the Greenland Ice Sheet (GrIS). Sub-ice geology is a dominant control on ice flow velocity with fast flow often coinciding with the presence of deformable subglacial till eroded from underlying sedimentary rocks. The subglacial geology of Greenland has received relatively little attention thus far and its control on ice flow is poorly understood. Seismic studies of the crust beneath the GrIS have been limited due to a lack of seismic stations and the reliance on earthquake event data. However, in the past decade, there has been a rapid increase in the number of both permanent and temporary seismic stations deployed in Greenland as well developments in ambient noise methods, allowing for improved spatial resolution of crustal geology.

Ellipticity measurements, the ratio of the horizontal to vertical component of a Rayleigh wave, have been shown to be particularly sensitive to the geological structure directly beneath the station. Ambient noise $\mathrm{H} / \mathrm{V}$ measurements have been used for decades in geotechnical and civil engineering for site characterisation, making them a well-suited technique to determine the subglacial geology of the GrIS. Using all available broadband stations deployed on Greenland from 2012 to 2018 we extract Rayleigh wave ellipticity measurement from ambient noise data using the degree-of-polarization (DOP) method where meaningful signals are defined as a waveform with an arbitrary polarization which remains stable for a given time window. We invert these ellipticity measurements in the period range of $4-9 \mathrm{~s}$ to generate $V_{s}$ profiles of the first $5 \mathrm{~km}$ beneath each station. Our inversions indicate that: (1) off-ice stations along the margins of the GrIS produce a good agreement with the litho1.0 model to within error and (2) an additional subglacial layer 1.0 $2.0 \mathrm{~km}$ thick with a $V_{s}<3.0 \mathrm{~km}$ is necessary to match the data recorded at several of the on-ice stations. We attribute these observations to the widespread presence of sedimentary rocks beneath the GrIS, potentially capable of sustaining extensive subglacial till layers that can support 
enhanced basal slip. 